\title{
Measurement of CT lung density in patients with chronic asthma
}

\author{
W. Biernacki, A.T. Redpath, J.J.K. Best, W. MacNee
}

Measurement of CT lung density in patients with chronic asthma. W. Biernacki, A.T. Redpath, J.J.K. Best, W. MacNee. (CERS Journals Ltd. 1997.

ABSTRACT: Evidence for the presence of emphysema in patients with asthma is controversial. We have previously shown that decreased lung density, measured by computed tomographic (CT) scanning, preoperatively, correlates with morphometric measurements of microscopic emphysema in subsequently resected lungs. The aim of this study was to compare CT lung density, in 17 patients with chronic asthma (forced expiratory volume in one second (FEV1) 1.98 (SD 0.77) L), 17 patients with chronic bronchitis and emphysema (FEV1 $0.97(0.56) \mathrm{L}$ ) and seven normal subjects (FEV1 $3.5(0.34)$ L).

All subjects underwent CT scanning of the lungs and respiratory function testing within 2 days of each other. In five of the asthmatic patients a CT scan was performed on two occasions before and after treatment with nebulized bronchodilator. In a different group of five asthmatics these measurements were performed at the end of and 6 weeks after an exacerbation.

The mean value of the lowest fifth percentile of the CT lung density in the patients with chronic obstructive pulmonary disease (COPD) was $\mathbf{- 9 4 2}$ (SD 36) Hounsfield units (HU), in the 17 asthmatic patients was -912 (34) HU, and in normal subjects was $\mathbf{- 8 8 0}(13)$. Despite a significant increase in peak expiratory flow rate from 266 (SD 102) to $406(83) \mathrm{L} \cdot \mathrm{s}^{-1}(\mathrm{p}<0.02)$ following nebulized $\beta_{2}$-agonist in five patients with chronic asthma, there was no significant change in CT lung density $(p>0.05)$

Our study indicates that at least some patients with chronic, stable asthma develop a reduction in computed tomography lung density, similar to that in patients with emphysema.

Eur Respir J 1997; 10: 2455-2459.
Respiratory Medicine Unit, Dept of Medicine and Depts of Medical Radiology and Medical Physics, The University of Edinburgh, Royal Infirmary, Edinburgh, UK.

Correspondence: W. Biernacki

Chest Unit

Pontefract General Infirmary

Friarwood Lane

Pontefract

West Yorkshire WF8 1PL

UK

Keywords: Asthma

computed tomographic scan

Received: October 301996

Accepted after revision June 221997

Supported by the Norman Salvesen Emphysema Research Trust.
Asthma is defined clinically as airflow limitation which reverses spontaneously or in response to treatment [1]. However, it is well known that a proportion of patients who develop this condition have a chronic course, with progressively less reversibility of their airflow limitation [2], chronic overinflation, and occasionally chronic sputum production. Such patients have the syndrome of chronic obstructive pulmonary disease (COPD) and overlap, in clinical terms, with patients who have primarily chronic bronchitis and emphysema [3].

Emphysema, on the other hand, has been defined pathologically as an increase above normal of the size of distal airspaces with destruction of their walls, but without obvious fibrosis [4]. The evidence for the presence of emphysema in patients with asthma is controversial. MESSNER et al. [5] suggested that both microscopic and macroscopic emphysema was common in asthmatics, whereas DunNILL [6] found no evidence of macroscopic emphysema in the lungs of 20 patients who died in status asthmaticus. This problem is complicated by the definition of emphysema, which states that microscopic emphysema is an enlargement of distal airspaces, without defining the normal size of those airspaces [4]. Many pathological studies have measured macroscopic emphysema semiquantitatively [7-9], at a stage where it has been estimated that two-thirds of the alveolar surface has been lost [10]. Moreover, it is difficult in a morphometric study to differentiate microscopic evidence of distal airspace enlargement, the early stages of alveolar wall destruction, from the chronic overinflation of asthma, without defining the normal distribution of distal airspace size.

We have previously shown that measurements of computed tomography (CT) lung density in life, can quantitate the extent of microscopic emphysema, measured morphometrically in resected lungs [11].

The aim of this study was, therefore, to evaluate CT lung density in a group of patients with acute and chronic asthma, and also to determine whether acute or chronic overinflation affects measurements of CT density.

\section{Subjects and methods}

\section{Subjects}

Three groups of patients/subjects were studied: seven healthy volunteers (forced expiratory volume in one second (FEV1) 3.5 (SD 0.34) L), 17 patients with chronic asthma (FEV1 $1.98(0.77) \mathrm{L}$ ); and 17 patients with chronic bronchitis and chronic airflow limitation (FEV1 0.97 (0.56) L). 
The healthy volunteers, who were recruited from hospital workers were all lifelong nonsmokers, had no historical or clinical evidence of lung disease, and had a normal chest radiograph, and normal values for spirometry, lung volumes and transfer factor of the lung for carbon monoxide (TL,CO). All patients were recruited consecutively from out-patients clinics, with the exception of five asthmatics who required admission to hospital with an exacerbation of their condition.

All of the asthmatic patients had a history of nonallergic asthma and none had clinical features of bronchopulmonary aspergilloma. All of the asthmatics were lifelong nonsmokers and had a $>20 \%$ increase in baseline FEV1 in response to nebulized $\beta_{2}$-agonist shown within 2 yrs prior to admission. However, when clinically stable, these patients had a degree of chronic irreversible airflow limitation.

The 17 patients with chronic bronchitis were all current or exsmokers with no clinical evidence or family history of asthma. They had all experienced chronic cough and hypersecretion of mucus for 3 months $\cdot \mathrm{yr}^{-1}$ for at least two consecutive years. They had a wide range of airways obstruction as measured by $\mathrm{FEV}_{1} /$ forced vital capacity (FVC) (table 1) and had less than a $15 \%$ improvement in their baseline FEV1 in response to nebulized $\beta_{2}$-agonist. Some of these patients had plain chest radiographic evidence of emphysema. However, the degree of emphysema was not assessed on plain radiography, since this relates poorly to the pathological assessment of the disease [12]. None of these patients had evidence of bullous emphysema (intrapulmonary airspaces $>1 \mathrm{~cm}$ ) on visual inspection of their CT scans. Respiratory function was measured within 2 days of the CT scan.

All patients, except those with acute asthma, were studied when they were clinically stable, without an exacerbation of their condition in the preceding month. Five patients with an exacerbation of asthma, who required admission to hospital, had a CT scan and lung function analysis performed prior to discharge. These patients were receiving inhaled bronchodilators and were on oral corticosteroids at this time. Their peak expiratory flow rate (PEFR) was $>70 \%$ of their best value at the time of discharge. In this group of patients, all tests were repeated 6 weeks after discharge from the hospital, when their disease was considered to be clinically stable. Their usual medication, which consisted of inhaled $\beta_{2}$-agonists, \pm ipratropium bromide and inhaled steroids, was continued unchanged.

\section{Methods}

All patients underwent respiratory function tests and had a CT scan within a 2 day period. These tests were performed when the patients had been in a stable condition for at least 6 weeks. When comparing lung function and CT lung density in patients with asthma and COPD with those in normal subjects, only data obtained at the time of clinical stability was used in analysis.

In five of the 17 patients with clinically stable asthma, a CT scan and PEFR measurements were performed early in the morning before the patients used any bronchodilator, and these measurements were repeated $1 \mathrm{~h}$ after inhalation of $5 \mathrm{mg}$ nebulized terbutaline.
In a different group of five asthmatic patients, CT scan and lung function were measured at the end of an exacerbation, which was severe enough to require hospital admission, and again 6 weeks later when their condition was considered to be clinically stable.

Lung function. FEV1 and vital capacity (VC) were measured using a $7 \mathrm{~L}$ dry spirometer (Vitalograph Ltd, Maids Morton, Bucks, UK) and lung volumes were measured using the helium dilution technique (P.K. Morgan, UK). Single-breath diffusing capacity was measured by the method of OGILviE et al. [13] (Automatic Transfer Test, Model A System; P.K. Morgan, Gillingham, UK) with the breathholding time calculated by the modified Jones and Meade [14] technique. In males, normal predicted values were taken from CRAPO et al. [15] for FEV1 and VC, CRAPO et al. [16] for total lung capacity (TLC) and residual volume (RV), and COTES et al. [17] for TL,CO. In females normal predicted values were taken from HALl et al. [18] for FEV1, VC, TLC and RV, and BiLliet et al. [19] for TL,CO.

CT scanning. CT scans were performed on a GE 9000 scanner with a $4 \mathrm{~s}$ scan time, at $3 \mathrm{~cm}$ intervals from the apex of the lung to the diaphragm using $10 \mathrm{~mm}$ collimation. On average, seven slices were obtained from each lung. During the scan, the patient held his/her breath at full inspiration close to TLC. A custom-written computer program was used to outline the lung fields excluding the hilar region, as described previously [11]. A cumulative frequency histogram of CT density numbers in Hounsfield units (HU) was obtained for each percentile within all CT scan cuts. On the Hounsfield scale $-1,000=$ air; $0=$ water; and $+1,000=$ bone density. Lung density was characterized as the mean or the lowest fifth percentile (L5P) of these cumulative frequency histograms from both lung fields, which had previously been evaluated against measurements of distal airspace size [11]. The system was calibrated daily with a water phantom and any scans containing artifacts were excluded from the analysis.

\section{Statistical analysis}

All values are given as mean \pm SD. Significant differences were calculated using Mann-Whitney U-test for two independent samples or by analysis of variance (ANOVA) when multiple comparisons were made.

\section{Results}

The patients with asthma had a wide range of airflow limitation as measured by an FEV1 of $33-105 \%$ predicted (table 1). Similarly, a wide range of airflow limitation, FEV1 $15-68 \%$ pred, was present in the patients with COPD. The patients with COPD had a more severe airflow limitation (mean FEV1 32 (SD 13) \% pred) than the patients with asthma (65 (20) \% pred; $\mathrm{p}<0.005)$. $T \mathrm{~L}, \mathrm{CO} / \mathrm{alveolar}$ volume (VA) was significantly lower in the patients with COPD (58 (20)\% pred) compared with asthmatic subjects $(90(20) \%$ pred; $p<0.005)$. Seven of the 17 patients with asthma had a $T \mathrm{~L}, \mathrm{CO} / V \mathrm{~A}<80 \%$ pred.

The mean value of the L5P of the CT lung density from the cumulative frequency histograms, from all 
Table 1. - Characteristics of patients studied

\begin{tabular}{|c|c|c|c|c|}
\hline Group & $\begin{array}{l}\text { Age } \\
\text { yrs }\end{array}$ & $\begin{array}{l}\text { FEV1 } \\
\% \text { pred }\end{array}$ & $\begin{array}{l}\text { TLC } \\
\% \text { pred }\end{array}$ & $\begin{array}{c}T \mathrm{~L}, \mathrm{CO} / V \mathrm{~A} \\
\% \text { pred }\end{array}$ \\
\hline $\begin{array}{l}\text { Normal } \\
(\mathrm{n}=7)\end{array}$ & $\begin{array}{c}42 \\
(32-54)\end{array}$ & $\begin{array}{c}103 \\
(90-110)\end{array}$ & $\begin{array}{c}104 \\
(102-106)\end{array}$ & $\begin{array}{c}96 \\
(92-10\end{array}$ \\
\hline COPD & 63 & 32 & 139 & 58 \\
\hline $\begin{array}{l}(n=17) \\
\text { Asthma }\end{array}$ & $\begin{array}{c}(55-74) \\
52\end{array}$ & $\begin{array}{c}(15-68) \\
65\end{array}$ & $\begin{array}{c}(100-211) \\
113\end{array}$ & 90 \\
\hline
\end{tabular}

Values are presented as mean, and range in parenthesis. FEV1: forced expiratory volume in one second; TLC: total lung capacity; TL,CO: transfer factor of the lung for carbon monoxide; VA: alveolar volume; COPD: chronic obstructive pulmonary disease; $\%$ pred: percentage of predicted value.

lung slices (mean L5P) in the 17 asthmatic subjects was -905 (34) HU (range -822 to $-956 \mathrm{HU}$ ). The patients with COPD had a lower lung CT density than asthmatic subjects (mean L5P -942 (36) HU, range -906 to -990; $\mathrm{p}<0.05)$. However, both asthmatics and patients with COPD had a lower CT lung density than normal subjects (mean L5P -880 (12) HU, range -862 to -898 HU; $\mathrm{p}<0.02)$. There was a considerable overlap between the CT lung density in patients with asthma and COPD (fig. 1).

There was no significant correlation between CT lung density (measured as the L5P or mean of the cumulative frequency histograms of CT lung density) and FEV1 and $\mathrm{FVC}, T \mathrm{~L}, \mathrm{CO} / V \mathrm{~A}$ and $\mathrm{RV} / \mathrm{TLC}$, either when the individual groups were analysed separately or when the data were combined. However, CT lung density (L5P) correlated significantly with TLC $(r=0.63 ; p<0.05)$ but only in the asthmatics (fig. 2).

The results of CT lung density before and after nebulized $\beta_{2}$-agonist are shown in table 2 . Although nebulized $\beta_{2}$-agonist increased PEFR, CT lung density (L5P) did not change significantly.

In the group of five patients with asthma studied at the end of an exacerbation and 6 weeks thereafter when clinically stable, FEV1 improved significantly (table 3). However, there was no significant change in TLC, RV/ TLC ratio, or CT lung density (table 3 ).

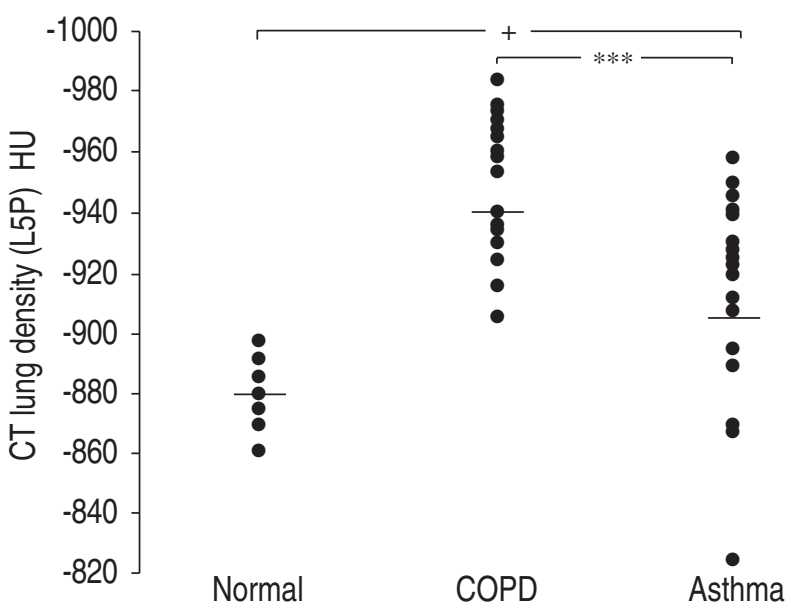

Fig. 1. - Computed tomographic (CT) lung density (lowest fifth percentile (L5P) in Hounsfield units (HU)) in seven normal subjects, 17 patients with chronic obstructive pulmonary disease (COPD) and 17 patients with asthma. Patients with COPD and asthma were studied when clinically stable. Horizontal bars represent the mean values. ${ }^{+}$: $\mathrm{p}<0.01 ; * * *: \mathrm{p}<0.001$.

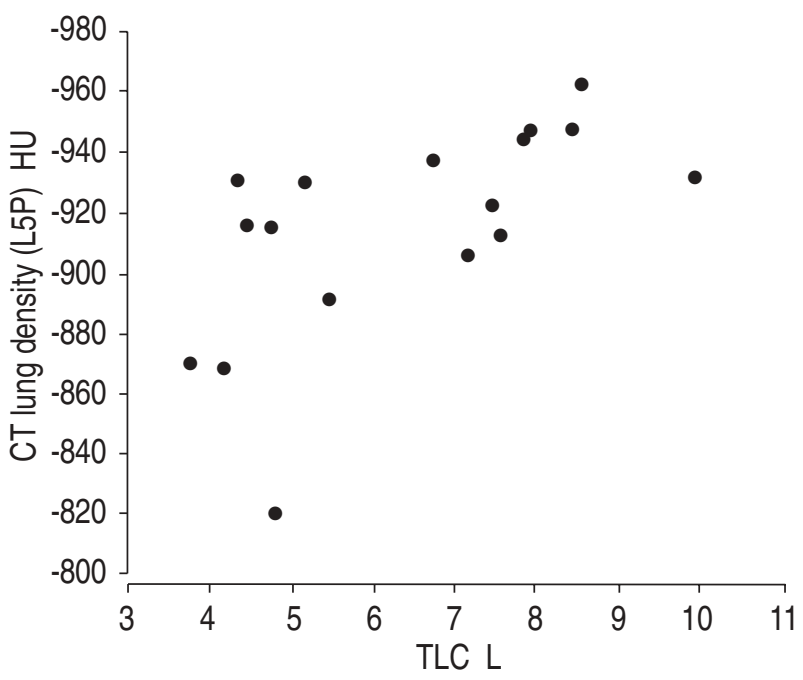

Fig. 2. - Correlation between total lung capacity (TLC) and computed tomographic (CT) lung density (lowest fifth percentile (L5P) in Hounsfield units (HU)) in 17 patients with stable asthma. ( $\mathrm{r}=0.63$; $\mathrm{p}<0.05)$.

Table 2. - PEFR and CT lung density (L5P) before and after nebulized terbutaline $(5 \mathrm{mg})$ in five patients with stable asthma

\begin{tabular}{|c|c|c|c|}
\hline & Control & $\begin{array}{c}\text { Post- } \\
\text { bronchodilation }\end{array}$ & p-value \\
\hline PEFR $\quad L \cdot \mathrm{s}^{-1}$ & 266 (102) & $406(83)$ & $<0.02$ \\
\hline $\begin{array}{l}\text { CT lung density } \mathrm{HU} \\
\text { (L5P) }\end{array}$ & $-888 \quad(46)$ & $-888(56)$ & $>0.05$ \\
\hline
\end{tabular}

Values are presented as mean, and SD in parenthesis. PEFR: peak expiratory flow rate; $\mathrm{CT}$ : computed tomography; $\mathrm{HU}$ : Hounsfield units; L5P: lowest fifth percentile.

Table 3. - Respiratory function and CT lung density (L5P) at the end of an exacerbation (To) and 6 weeks later (T6) in five patients with asthma

\begin{tabular}{|c|c|c|c|}
\hline & T0 & T6 & p-value \\
\hline FEV1 $\%$ pred & $70(22)$ & $81(17)$ & $<0.05$ \\
\hline TLC \%pred & $125(36)$ & $120(17)$ & $>0.05$ \\
\hline RV/TLC \% & $42(4)$ & $41(7)$ & $>0.05$ \\
\hline $\begin{array}{l}\text { CT lung density } \mathrm{HU} \\
\text { (L5P) }\end{array}$ & $-898(24)$ & $-896(260)$ & $>0.05$ \\
\hline
\end{tabular}

Values are presented as mean, and SD in parenthesis. RV: residual volume. For further definitions see legends to tables 1 and 2.

\section{Discussion}

This study indicates that some patients with stable asthma, particularly those with a degree of irreversible airflow limitation have values of CT lung density which are similar to patients with historical and functional evidence of chronic bronchitis and emphysema. Since we have previously shown that measurements of CT lung density correlate with morphometric measurements of the size of distal airspaces [11], this may indicate that these patients with chronic asthma have emphysema. Some support for this comes from the fact that a proportion of the asthmatics in this study had a low $T \mathrm{~L}, \mathrm{CO} / V \mathrm{~A}$, the lung function parameter which correlates best in previous structure/function studies with emphysema [20, 21], and which we have previously shown correlates best with CT lung density in patients with COPD [22]. 
However, a low CT lung density could result from chronic overinflation, which is difficult to differentiate pathologically from early microscopic emphysema (D. Lamb, personal communication). Some of the present patients with clinically stable asthma had CT lung density values similar to patients who have previously been shown to have macroscopic emphysema pathologically [11]. This may result from the fact that 10 of the 17 asthmatic patients who were studied had a degree of chronic airflow limitation (FEV $1<65 \%$ pred) and overinflation even when clinically stable. Patients with asthma, particularly acute asthma, develop overinflation [23], which may account for the low CT lung density in these patients. Support for this comes from the significant but weak relationship between CT lung density and TLC in the asthmatic patients. However, the weak correlation suggests that overinflation is not the only factor influencing low CT lung density in asthmatic subjects.

In the present study all CT scans were performed in full inspiration, since we have shown that this correlates best with morphometric assessment of emphysema [11]. However, there have been studies suggesting that CT scans performed in full expiration can be advantageous in assessing emphysema more accurately [24, 25]. Furthermore, NEWMAN et al. [ 26] suggested that a CT scan taken at full expiration can be useful in assessing air-trapping. However, none of these studies compared CT data with pathological assessments of emphysema. Very recently, GevenoIs et al. [27] studied 89 patients with COPD and found that expiratory quantitative CT was not as accurate as inspiratory CT scans to quantify pulmonary emphysema.

We have previously shown that CT lung density correlates best with $T \mathrm{~L}, \mathrm{CO} / V \mathrm{~A}$ in patients with COPD [22]. However, we were unable to demonstrate a similar significant relationship $(\mathrm{r}=0.35 ; \mathrm{p}>0.05)$ in this group of patients with COPD, presumably due to the smaller number of patients studied.

In a previous paper, Kinsella et al. [28] showed that asthmatic patients with a TLC greater than $120 \%$ pred showed no evidence of macroscopic emphysema as assessed by CT scanning. Using a visual scoring system, KodoH et al. [29] found CT evidence of emphysema, but only in smoking asthmatics. LYNCH et al. [30] also found mild emphysema in some asthmatic patients, but again most were smokers. However, PAGANIN et al. [31] showed the presence of emphysema in CT scans in nonsmoking patients with severe asthma. They speculated that the presence of emphysema was not due to parenchymal-destruction disease, but may be related to cicatrical emphysema and to airway remodelling. In a more recent paper, the same group [32] found more irreversible changes, including bronchiectasis, emphysema and peribronchial wall thickening in patients with nonallergic asthma compared with a group of patients with allergic asthma. In the present study the majority of the asthmatic patients had a reduced CT lung density similar to the patients with chronic bronchitis and emphysema. Most of the irreversible changes described by PAGANIN and co-workers $[31,32]$ could increase the CT density. In addition, visual inspection of the CT scans in the present patients did not reveal significant bronchiectatic or fibrotic changes. Furthermore, our technique uses CT lung density as a measure of microscopic emphysema or chronic overinflation, which may be indistinguishable by CT scanning.

In order to determine whether an improvement in airflow limitation, which may decrease overinflation, alters CT lung density, we measured CT lung densities in five patients with stable asthma before and after nebulized $\beta_{2}$-agonist was administered. Despite the significant improvement in PEFR, CT lung density did not change. Similarly, Gevenois et al. [27] found no significant changes in CT density measurements in a group of asthmatics who underwent allergen provocation testing, with a subsequent decrease in FEV1 of $0.9 \mathrm{~L}$. However, as in our patients, they did not observe any significant changes in TLC following this inhalation. In the present study, we were not able to measure lung volumes accurately by determining the cumulative area $\times$ slice thickness for each CT slice, since we undertook scans which were not contiguous and thus measurements of TLC would have been inaccurate.

To test the hypothesis that low CT lung density in asthmatic patients is due to chronic overinflation, CT lung density was studied in five patients at the end of an exacerbation of their asthma and again when the patients were clinically stable 6 weeks later. In spite of an increase in FEV1, CT lung density did not change. However, these patients also showed no change in TLC or RV/TLC, indicating that there was no significant change in lung volumes, at least, as measured by helium dilution, between the end of the exacerbation and clinical stability. PAGANIN et al. [32] also found, in 10 patients with asthma who underwent CT scan during an exacerbation and 1-2 weeks thereafter, that there was no improvement in visual assessment of emphysema, bronchial wall-thickening or bronchiectasis, although this assessment was quantitative. However, the changes of mucoid impaction, acinar patterns and segmental collapse disappeared. Unfortunately, they did not measure lung volumes in these patients. Measurements in patients with more acute asthma, with repetition when their condition had stabilized, could have shown a change in lung volumes that may have been reflected as a change in CT lung density. However, such a study would be limited by the inability to undertake CT scanning in acutely ill, breathless patients. Moreover, measurement of lung volumes, both by helium dilution and by body plethysmography are potentially erroneous in patients with severe airflow limitation [33]. Radiographic planimetry [34] or contiguous CT slices [35] could have been used to avoid such errors in the measurement of lung volume but would have involved a greater radiation burden for the patients.

This study also shows that, in addition to low lung CT density, patients with chronic asthma develop functional abnormalities similar to those in patients with COPD, such as a reduction in $T \mathrm{~L}, \mathrm{CO} / V \mathrm{~A}$. One other study has also suggested that longstanding chronic asthma results in functional changes which mimic those seen in patients with chronic bronchitis and emphysema [36].

The debate in the literature over the presence of emphysema in patients with chronic asthma $[5,6]$ remain unresolved. This may relate to difference in techniques for measuring both macroscopic and microscopic emphysema. This question can only be answered when modern 
morphometric techniques used to measure the size of distal airspaces produce a normal range of these values, which can then be applied to the lungs of patients dying with chronic asthma.

In summary, our study confirms that low lung computed tomography density, with values similar to those in patients with chronic bronchitis and emphysema, occurs in chronic asthma. This low lung computed tomography density represents microscopic emphysema or chronic overinflation. It is not altered by bronchodilator therapy and is similar when measured at the end of an exacerbation of asthma or at a time of clinical stability.

\section{References}

1. Fletcher CM, Pride NB. Definition of emphysema, chronic bronchitis, asthma and airflow obstruction. 25 years from CIBA symposium. Thorax 1984; 39: 81-85.

2. Burrows B. Possible pathogenic mechanisms in chronic airflow obstruction. Chest 1984; 85: 135-155.

3. Snider GL. Chronic obstructive pulmonary disease: a definition and implications of structural determinants of airflow obstruction for epidemiology. Am Rev Respir Dis 1989; 140: 53-59.

4. Snider GL, Kleinerman J, Thurlbeck WM, Bengoli ZH. The definition of emphysema. Report of a National Heart, Lung and Blood Institute, Division of Lung Disease Workshop. Am Rev Respir Dis 1985; 132: 182-185.

5. Messner JW, Peters GA, Bennet WA. Causes of death and pathologic findings in 304 cases of bronchial asthma. Dis Chest 1960; 38; 616-624.

6. Dunnill MS. The pathology of asthma with special reference to changes in the bronchial mucosa. J Clin Pathol 1960; 13: 27-33.

7. Pare PD, Brooks LA, Bates J, et al. Exponential analysis of the lung pressure-volume curve as a predictor of pulmonary emphysema. Am Rev Respir Dis 1982; 126: 54-61.

8. Hruban RH, Meziane MA, Zerhouni EA, et al. High resolution computed tomography of inflation-fixed lungs. Am Rev Respir Dis 1987; 136: 935-940.

9. Bergin C, Muller N, Nichols DM, et al. The diagnosis of emphysema: a computed tomographic-pathological correlation. Am Rev Respir Dis 1986; 133: 541-546.

10. Lamb D. Chronic obstructive pulmonary disease: pathology. In: Brewis RAL, Gibson GJ, Geddes DM, eds. Respiratory Medicine. London, Bailiere Tindall, 1990; Chapter 16.3: p. 501.

11. Gould GA, MacNee W, McLean A, et al. CT measurements of lung density in life can quantitate distal airspace enlargement - an essential defining feature of human emphysema. Am Rev Respir Dis 1988; 137: 380-391.

12. Thurlbeck WM, Simon WM. Radiographic appearance of the chest in emphysema. Am J Roentgenol 1978; 130: 429-440.

13. Ogilvie CM, Forster RE, Blakemore WS, Morton JW. A standardized breathholding technique for the clinical measurement of the diffusing capacity of the lung for carbon monoxide. J Clin Invest $1957 ; 36 ; 1-17$.

14. Jones RS, Meade F. A theoretical and experimental analysis of anomalies in the estimation of pulmonary diffusing capacity by the single-breath method. Q J Exp Physiol 1961; 46: 131-143.

15. Crapo RO, Morris AH, Gardner RM. Reference spirometric values using techniques and equipment that meet ATS recommendations. Am Rev Respir Dis 1981; 123: 659-664.
16. Crapo RO, Morris AH, Clayton PD, Nixon CR. Lung volumes in healthy nonsmoking adults. Bull Eur Physiopathol Respir 1982; 18: 419-425.

17. Cotes JE. Lung function at different stages of life, including reference values. In: Lung Function, 3rd Edn. Oxford, Blackwell Scientific Publications, 1975; pp. 340-395.

18. Hall AM, Heywood C, Cotes JE. Lung function in healthy British women. Thorax 1979; 34: 359-365.

19. Billiet L, Baiser W, Naedts JP. Effet de la taille du sexe et de l'age sur la capacité de diffusion pulmonaire de l'adult normal. J Physiol (Paris) 1963; 55: 199-200.

20. Petty TL, Silvers GW, Stanford RE. Functional correlations with mild and moderate emphysema in excised lungs. Am Rev Respir Dis 1981; 124: 700-704.

21. Berend N, Woolcock AJ, Martin GE. Correlation between the function and structure of the lung in smokers. Am Rev Respir Dis 1979; 119: 695-705.

22. Gould GA, Redpath AT, Ryan M, et al. Lung CT density correlates with measurements of airflow limitation and the diffusing capacities. Eur Respir $J$ 1991; 4: 141-146.

23. Woolcock AJ, Read J. Lung volumes in exacerbation of asthma. Am J Med 1966; 41: 259.

24. Knudson RJ, Standen JR, Kaltenborn MS, et al. Expiratory computed tomography for assessment of suspected pulmonary emphysema. Chest 1991: 99: 1357-1366.

25. Miniati M, Filippi E, Falaschi F, et al. Radiologic evaluation of emphysema in patients with chronic obstructive pulmonary disease. Am J Respir Crit Care Med 1955; 151: 1359-1367.

26. Newman KB, Lynch DA, Newman LS, Ellegood D, Newell JD. Quantitative computed tomography detects air-trapping due to asthma. Chest 1994; 106: 105-109.

27. Gevenois PA, De Vuyst P, Sy M, et al. Pulmonary emphysema: quantitative CT during expiration. Radiology 1996; 199: 825-829.

28. Kinsella M, Muller NL, Staples C, Vedal S, ChanYeung M. Hyperinflation in asthma and emphysema. Chest 1988; 94: 286-288.

29. Kodoh Y, Taniguchi H, Yokoyama S, Taki F, Takagi K, Satake T. Emphysematous change in chronic asthma in relation to cigarette smoking. Chest 1990; 97: 845-849.

30. Lynch D, Newell J, Tschomper B, Clink T, Newman L, Bethel R. Uncomplicated asthma in adults: comparison of CT appearance of the lung in asthmatic and healthy subjects. Radiology 1993;188: 829-833.

31. Paganin F, Trussard V, Seneterre E, et al. Chest radiography and high resolution computer tomography of the lungs in asthma. Am Rev Respir Dis 1992; 146: 1084-1087.

32. Paganin F, Seneterre E, Chanez P, et al. Computed tomography of the lungs in asthma: influence of disease severity and aetiology. Am J Respir Care Med 1996; 153: 110-114.

33. Paré PD, Wiggs BJR, Coppin CA. Errors in the measurement of total lung capacity in chronic obstructive lung disease. Thorax 1983; 38: 468-471.

34. Blackie SP, AL-Majed S, Staples CA, Hillam C, Paré PD. Changes in total lung capacity during spontaneous asthma. Am Rev Respir Dis 1990; 142; 79-83.

35. Dennison DM, Morgan MDL, Millar AB. Estimation of regional gas and tissue volumes of the lung in supine man using computed tomography. Thorax 1986; 41: 620-628.

36. Braman SS, Kaemmerlen JT, Davies SM. Asthma in the elderly: a comparison between patients with recently acquired and longstanding disease. Am Rev Respir Dis 1991; 143: 336-340. 